\title{
Zika virus infection could trigger Guillain-Barré syndrome
}

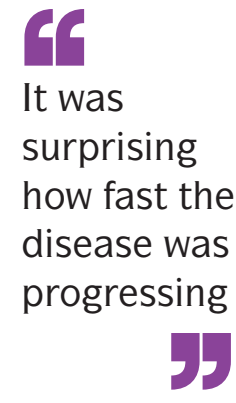

Observations from French Polynesia during a Zika virus outbreak 2 years ago add the virus to the list of pathogens that can trigger Guillain-Barré syndrome (GBS), a severe neurological disorder characterized by progressive muscle weakness that can result in respiratory failure. The findings of the new case-control study, published in The Lancet, could have important implications for the Latin American countries affected by the current Zika epidemic.

The new study focused on a large Zika virus outbreak that occurred in French Polynesia in 2013-2014. At the same time, a notable increase in GBS was observed in the area. General practitioners sent all patients with suspected GBS to neurologists or intensive care units for confirmation of the diagnosis via electromyographic evaluation. Moreover, blood samples were taken to assess signs of recent Zika virus infection.

During the outbreak, 42 patients were diagnosed with GBS. 88\% of them reported having experienced a transient illness about 1 week before the onset of neurological symptoms. All but one had IgM or IgG

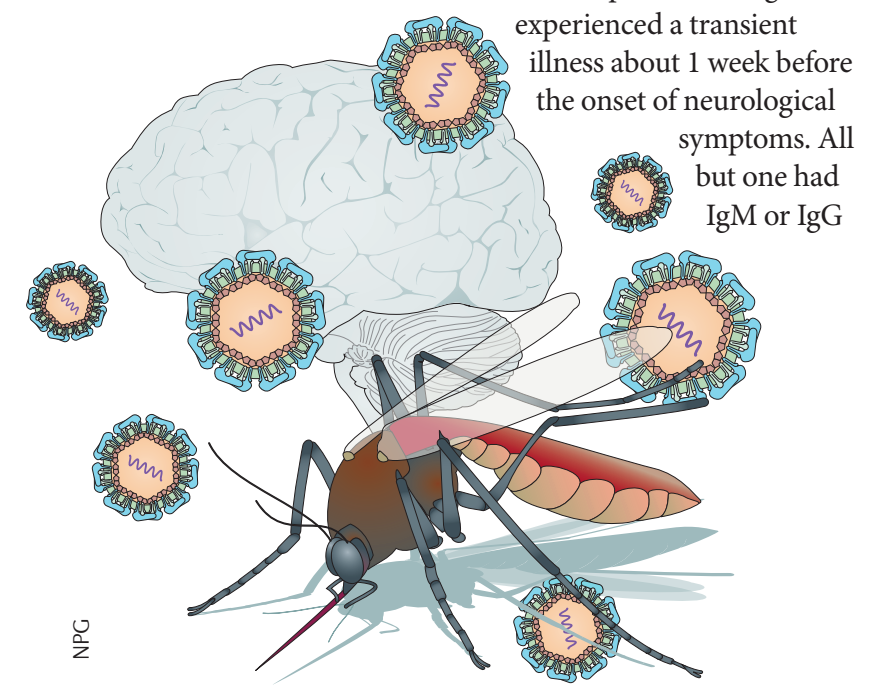

antibodies against the Zika virus, and all had neutralizing antibodies against the virus. In a control group of 98 individuals presenting with nonfebrile illness, only $56 \%$ had neutralizing anti-Zika antibodies. "Our study was successful in associating GBS with a recent Zika infection because a surveillance system was already in place," comments one of the study authors, Arnaud Fontanet from the Institut Pasteur in Paris, France.

Intriguingly, antiglycolipid antibodies - hypothesized to be involved in GBS pathogenesis were detected in only $31 \%$ of patients. "These antibodies could be transient in nature; moreover, it is possible that Zika-associated GBS is directly triggered by the viral infection rather than being an autoimmune reaction," comments Hugh Willison from the University of Glasgow, UK, who was also involved in the study.

The patients with Zika-associated GBS deteriorated rapidly. "It was surprising how fast the disease was progressing," Fontanet comments. 38\% of patients with GBS required intensive care, most commonly owing to difficulty breathing or swallowing. The average length of intensive care unit stay was 35 days. Most of the patients recovered relatively quickly, and 3 months after discharge from hospital, $57 \%$ were able to walk.

The study estimated the rate of GBS after Zika virus infection to be about 1 per 4,000 infections. The WHO estimate of about 3-4 million total cases of Zika infection in the next year could, therefore, translate to hundreds of cases of GBS and other neurological sequelae. "Countries with a Zika virus epidemic need to reserve sufficient number of beds to hospitalize patients to intensive care for over a month," Fontanet warns. Sufficient resources should also be allocated to provide intravenous immunoglobulin treatment for patients with Zika-associated GBS.

"We are certainly going to see a high number of Zika-associated neurological disorders in Latin America," says Willison. In addition to GBS, other neurological manifestations include those associated with autoimmune reactions, such as acute demyelinating encephalomyelitis, and those linked directly with viral infection, such as viral encephalitis.

Another concern is how Zika infection affects the developing fetus. In Brazil, cases of Zika-associated microcephaly and ventricular calcification have been reported, and case studies have detected the virus in amniotic fluid and breast milk. However, the full consequences of Zika infection on fetal neural development remain unknown. "We do not yet understand the precise nature of how the direct effects of Zika virus and the host response interact to produce the complex range of neuropathological responses and neurological symptoms we are seeing," concludes Willison.

Hemi Malkki

ORIGINAL ARTICLE Cao-Lormeau, V.-M. et al. Guillain-Barré syndrome outbreak associated with Zika virus infection in French Polynesia: a case-control study. Lancet http://dx.doi.org/ 10.1016/S0140-6736(16)00562-6

FURTHER READING Brasil, P. et al. Zika virus infection in pregnant women in Rio de Janeiropreliminary report. N. Eng.J. Med. http://dx.doi.org/ 10.1056/NEJMoa1602412/van den Berg, B. et al. Guillain-Barré syndrome: pathogenesis, diagnosis, treatment and prognosis. Nat. Rev. Neurol. 10, 469-482 (2014). | Willison, H. J.et al. Guillain-Barré syndrome. Lancet http://dx.doi.org/10.1016/ S0140-6736(16)00339-1 